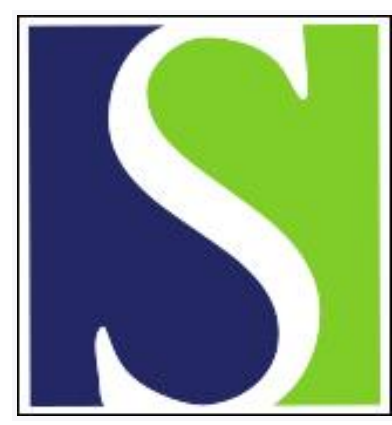

Scand J Work Environ Health 2006;32(2):89-90

https://doi.org/10.5271/sjweh.983

Issue date: 30 Apr 2006

\title{
Prevention of disability at work
}

by Kristensen $P$

Affiliation: Department of Occupational Medicine and Epidemiology, National Institute of Occupational Health, PO Box 8149 Dep, N-0033 Oslo, Norway. petter.kristensen@stami.no

Key terms: disability; editorial; prevention; work

This article in PubMed: www.ncbi.nlm.nih.gov/pubmed/16680378

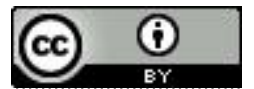




\section{Prevention of disability at work}

Occupational health and safety is an applied field, and the ultimate goal is preventing work-related hazards. We should welcome discourse on how to prevent work-related illnesses and accidents. In this issue of the Scandinavian Journal of Work, Environment \& Health, Frank and his co-workers contribute to the discourse in a discussion paper with the intention of starting a dialogue (1). The paper is written in an enthusiastic spirit, and the ideas and the concept are interesting and well argued. The discussion is framed by four key themes. In my opinion, three of them are not controversial and not so original. In principle, few would be opposed to statements that workplace prevention would need multifactorial solutions, what kind of quality criteria we need in effectiveness studies, or that there is a need for dialogue between researchers and practitioners. As a fourth and more novel theme to me, the authors argue that approaches for primary and secondary prevention should be integrated in order to create effective strategies. Intuitively, this approach makes sense as far as organizational aspects of workplace prevention are concerned. It also makes sense when both primary and secondary prevention are aiming at reducing adverse exposure. Overhead ceiling lifts in a health care unit would help employees with lowback pain return to work earlier and could also help prevent new cases. Other examples may not be that obvious, in particular when secondary prevention means providing employees who have special needs with modified worktasks. When employees are taken off night work or shift work for health reasons, the work scheme burden could be worse for the healthy ones remaining. Nevertheless, there are interesting dynamics between primary and secondary prevention that should be studied more closely than they have been.

Frank and his co-workers argue that the time is right and that conditions are well set to initiate workplace prevention (1). I would not be that optimistic. The conditions they describe could be right for large enterprises in Canada and other developed countries. But we all know that legislation and workplace organization are not that well suited for informal work or for worklife in most developing countries (2) or for many small enterprises. Are prerequisites favorable for discussions on prevention strategies in shoe workshops in Palestine or for informal gold mining in Latin America or Africa? Are the conditions for preventive measures excellent in the construction industry (3) or for agricultural laborers?

Another obstacle worth mentioning is an overall scarcity of quality research on effectiveness and intervention in the occupational field $(4,5)$. This lack is made an issue by Frank and his co-workers, but it is also demonstrated by the large proportion of examples they have gathered from sources without peer review (1). It may be difficult to find quality intervention studies even in peer-reviewed journals. The request for quality could be met with evidence-based reviews on interventions (www.cochrane.org). There are examples, as yet few, of Cochrane reviews in occupational health (6). A look at www.cochrane.org/reviews shows that almost all the intervention reviews are aimed the general population or subgroups, the young (eg, "Community-based Interventions for the Prevention of Burns and Scalds in Children") or the old (eg, "Population-based Interventions for the Prevention of Fallrelated Injuries in Older People"). Reviews targeting the employed will mostly aim at prevention among the general population ("Advanced Trauma Life Support Training for Ambulance Crews"). We should hope for improvement, however, now that the Cochrane Occupational Health Field (www.cohf.fi) has been established. This entity has the aim of gathering evidence on the effectiveness of occupational health interventions and stimulating the completion of systematic reviews on these interventions. 
When assessing the quality of research on intervention in the occupational field, we should keep in mind that such applied research is bound to a context. This time-and-place context will have consequences concerning external validity. We are not dealing with research aiming at disclosing biological causes of occupational disease, and we should not expect that the biomedical paradigm of universalism in research would be fulfilled. However, we should have internal validity quality criteria for evaluation and intervention research that is as strict as it is for other epidemiologic research.

We need well-performed studies providing descriptive information on disability at work to achieve prevention in the workplace. In this issue, you will find an interesting research paper by Ho et al on life expectancy among Taiwanese workers with occupational disabilities and the determinants for predicting survival (7). The aim is to provide evidence to improve equity in compensation systems in Taiwan, but the study could have values beyond this aim. The ordinary study on the prognosis after occupational injuries has fatality as a dichotomous outcome. Ho et al use survival methods to provide knowledge on long-term survival. Survival methods could be extended to other outcomes as well (eg, time to return to work). Studying worklife expectancy is another option; furthermore, survival methods are well suited for comparing groups in intervention studies (8).

In conclusion, submissions of quality manuscripts on the primary and secondary prevention of disability at work are welcome in the Scandinavian Journal of Work, Environment \& Health.

\section{References}

1. Frank J, Cullen K, Institute for Work \& Health Ad Hoc Working Group. Preventing injury, illness and disability at work. Scand J Work Environ Health. 2006;32:160-167.

2. Loewenson RH. Health impact of occupational risks in the informal sector in Zimbabwe. Int J Occup Environ Health 1998;4:264-74.

3. van Duivenbooden C, Frings-Dresen MHW, Ringen K. Construction workers and occupational health care [preface]. Scand J Work Environ Health. 2005;31 suppl 2:3-4.

4. Hulshof CT, Verbeek JH, van Dijk FJ, van der Welde WE, Braam IT. Evaluation research in occupational health services: general principles and a systematic review of empirical studies. Occup Environ Med. 1999;56:361-77.

5. Loisel P, Buchbinder R, Hazard R, Keller R, Scheel I, van Tulder M, et al. Prevention of work disability due to musculoskeletal disorders: the challenge of implementing evidence. J Occup Rehabil. 2005;15:507-24.

6. Schonstein E, Verbeek J. Occupational health Cochrane systematic reviews: an overview [abstract]. The Cochrane Collaboration. Available from: www.cochrane.org/colloquia/abstracts/melbourne/P-120.htm.

7. Ho JJ, Hwang JS, Wang JD. Life expectancy estimations and the determinants of survival after 15 years of follow-up on 81249 workers with permanent occupational disabilities. Scand J Work Environ Health. 2006;32(2):91-98.

8. Nurminen M. Working population health metrics. Scand J Work Environ Health. 2004;30:339-49.

Petter Kristensen, MD

Department of Occupational Medicine and Epidemiology

National Institute of Occupational Health

PO Box 8149 Dep

N-0033 Oslo, Norway

E-mail: petter.kristensen@stami.no 